\section{BMJ Open} Ophthalmology

\title{
Treatment failure in neovascular age- related macular degeneration is associated with a complex chemokine receptor profile
}

Thomas Bjerregaard, ${ }^{1}$ Marie Krogh Nielsen, ${ }^{\circledR 1}$ Christopher Rue Molbech, ${ }^{1,2}$ Yousif Subhi, ${ }^{1}$ Torben Lykke Sørensen ${ }^{1,2}$

To cite: Bjerregaard T, Krogh Nielsen M, Molbech CR, et al. Treatment failure in neovascular age-related macular degeneration is associated with a complex chemokine receptor profile. BMJ Open Ophthalmology 2019;4:e000307. doi:10.1136/ bmjophth-2019-000307

- Additional material is published online only. To view, please visit the journal online (http://dx.doi.org/10. 1136bmjophth-2019-000307).

Received 18 March 2019 Revised 21 May 2019 Accepted 26 June 2019
Check for updates

(C) Author(s) (or their employer(s)) 2019. Re-use permitted under CC BY-NC. No commercial re-use. See rights and permissions. Published by BMJ.

${ }^{1}$ Department of Ophthalmology, Zealand University Hospital, Roskilde, Denmark ${ }^{2}$ Faculty of Health and Medical Sciences, University of Copenhagen, Copenhagen, Denmark

Correspondence to Dr Marie Krogh Nielsen; mrrm@ regionsjaelland.dk

\section{ABSTRACT}

Objective To investigate if chemokine expression patterns on leucocyte subsets influence the short-term anatomical treatment response of intravitreal antivascular endothelial growth factor therapy against neovascular agerelated macular degeneration (AMD).

Methods and analysis This study was conducted as a prospective observational cohort study of 79 patients with neovascular AMD. We used optical coherence tomography to quantify central retinal thickness (CRT) and to evaluate the presence of intraretinal and subretinal fluids in treatment-naive patients at baseline and after loading dose. Anatomical response was categorised into either good responders (complete regression of fluid or a reduction of $>75 \%$ in CRT), partial responders (reduction of $0 \%-75 \%$ in CRT) or non-responders (increase of CRT). Expression levels of chemokine receptors (CCR1, CCR2, CCR3, CCR5, CXCR3 and CX3CR1) were measured on leucocyte subsets (monocytes, CD4 +T cells, and CD8 + T cells) using flow cytometry. Finally, we explored potential correlation patterns of chemokine expression between the leucocyte subsets using group-specific correlation networks.

Results Non-responders had higher CCR1 expression on monocytes $(p=0.016)$ and lower CCR3 expression on CD8+ T cells $(p=0.037)$. Correlation network analyses of chemokine receptor expression patterns on leucocyte subsets revealed intergroup differences.

Conclusion Short-term anatomical treatment response in neovascular AMD varies according to the leucocyte subset chemokine expression pattern, which confirms that immune dysfunction is a complex issue in AMD. Our results suggest that focusing on chemokines may be a relevant approach towards personalised treatment in neovascular AMD.

\section{INTRODUCTION}

Age-related macular degeneration (AMD) is the leading cause of legal blindness among the elderly in high-income countries, and prevalence is expected to increase significantly in the near future due to demographic changes. $^{1-3}$ The introduction of intravitreal antivascular endothelial growth factor (VEGF) therapy has drastically improved the

\section{Key messages}

What is already known about this subject?

Recent research has provided evidence of a systemic immunological component in age-related macular degeneration (AMD). Both the innate and the adaptive immune system are involved in the pathogenesis of AMD, but data on treatment response is sparse.

\section{What are the new findings?}

> Our findings demonstrate that non-responders after loading dose have a more complex peripheral chemokine receptor profile compared with good responders.

How might these results change the focus of research or clinical practice?

- These results implicate chemokines in antivascular endothelial growth factor treatment failure and support the idea of systemic immunology as a component of neovascular AMD pathogenesis and progression. Focusing on chemokines may be a relevant approach towards personalised treatment in neovascular AMD

prognosis of neovascular AMD. ${ }^{3}$ Although the inhibition of VEGF generally in most cases at least stabilises vision and retinal morphology, some patients do not respond well to treatment. ${ }^{4}$ One explanation for the heterogeneous response to anti-VEGF therapy is that other angiogenic factors contribute to the development and sustainment of choroidal neovascularisations. ${ }^{5}$ Attention is needed on identifying other treatment targets than just VEGF to improve clinical outcomes in such patients.

Recent research has provided evidence of a systemic immunological component in AMD. ${ }^{6}$ Several alterations in the immune system of patients with AMD have been reported, ${ }^{7-17}$ including levels of chemokines and their receptors. ${ }^{12} 141617$ Chemokines are signalling proteins secreted by cells, which 
induce chemotaxis towards a concentration gradient. Considering that chemokine receptors are expressed on leucocyte subsets that contribute to inflammation and angioneogenesis, one hypothesis is that the state of chemokine receptor expression on leucocyte subsets may contribute in a clinically important manner in neovascular AMD.

In this study, we explored how patients with neovascular AMD, stratified according to anti-VEGF treatment response, differ in terms of expression level of chemokine receptors on leucocyte subsets and the complex interplay between leucocyte subset chemokine receptors.

\section{MATERIALS AND METHODS}

Patient and public involvement

Patients were not involved in the design of this prospective observational cohort study. Patients were recruited from the outpatient retinal clinic of the Department of Ophthalmology, Zealand University Hospital, Denmark.

\section{Participants and eligibility}

All patients were subjected to a structured interview on medical history, current health conditions, medications and lifestyle factors. Smoking status was categorised as 'current' (had smoked within the past year of inclusion), 'former' (had a lifetime consumption of more than 100 cigarettes) or 'never' smokers (less than 100 cigarettes ever). Alcohol consumption was registered as units (12g ethanol) per week (self-reported). Physical activity was estimated from a single question previously validated ${ }^{7} 18$ in patients with AMD.

All patients underwent thorough retinal examination by a trained ophthalmologist using slit-lamp examination, digital colour fundus photography (Carl-Zeiss, Jena, Germany), spectral-domain optical coherence tomography (OCT), fundus autofluorescence imaging and retinal angiography with fluorescein and indocyanine green (Spectralis HRA-OCT, SLO Heidelberg Engineering, Heidelberg, Germany). Diagnosis of neovascular AMD was made in cases with the copresence of drusen and fibrovascular pigment epithelium detachment and choroidal neovascular membrane with subretinal or sub-retinal pigment epithelium haemorrhages. Patients with signs of polypoidal choroidal vasculopathy or pachychoroid neovasculopathy were not included.

All newly diagnosed patients received a standard treatment regimen of three intravitreal anti-VEGF injections at 1-month intervals ('loading dose') followed by a clinical control approximately 2 months after the third injection. Blood samples were obtained when patients visited the clinic for follow-up retinal examination. Blood sampling was rescheduled if patients had received ranibizumab within the past 4 weeks or aflibercept within the past 8 weeks, and blood was not sampled shortly after angiography in order to avoid influence on antibody staining. ${ }^{19}$ If a patient had two eyes eligible for the study, we included only data regarding the patient's right eye.
In this study, we aimed to investigate chronic systemic changes, and to minimise interference, we did not sample blood from patients who had an ongoing infection. Patients who suffered from cancer or any immunological disorders, or received immunomodulating treatment were excluded. We measured plasma C-reactive protein (CRP) to evaluate possible ongoing acute inflammation unknown to the patients and excluded patients with a CRP level of $>15 \mathrm{mg} / \mathrm{L}$. We also excluded patients with ungradable OCT quality as imaging measurements would be unreliable.

\section{Imaging and analysis}

OCT imaging and analysis were done using Heidelberg Eye Explorer V.1.9.10.0 (Heidelberg Engineering, Heidelberg, Germany). Each scan was composed of at least 19 B-scans using automatic real-time tracking and B-scan averaging. Scan area was $20^{\circ} \times 15^{\circ}(5.7 \times 4.3 \mathrm{~mm})$, and the distance between B-scans was a maximum of $236 \mu \mathrm{m}$. Retinal thickness was measured from Bruch's membrane to the inner limiting layer. The layer boundaries were manually corrected when needed. OCT images were analysed for central retinal thickness (CRT), defined as the average thickness of the central $1 \mathrm{~mm}$ of the retina using the Early Treatment Diabetic Retinopathy Study (ETDRS) Grid in Heidelberg Eye Explorer. We registered subretinal oedema (yes/no) and intraretinal oedema (yes/no), the latter defined as distinct intraretinal cysts.

\section{Definition of treatment response}

Quantifiable definitions of anti-VEGF treatment response are classically based on change in best-corrected visual acuity (BCVA) or on morphological changes. ${ }^{20}$ In this study, we analysed morphological changes based on CRT. We compared OCT images from the day of diagnosis (baseline) to first clinical control following anti-VEGF loading dose (follow-up), as this clinical control has been shown to be a good predictor of how well patients respond to treatment over time. ${ }^{20-22}$

The response was categorised as 'good' (total regression of subretinal or intraretinal fluid or a reduction of $>75 \%$ of baseline CRT), 'partial' (reduction of $0 \%-75 \%$ of baseline CRT) or 'non-response' (increase of CRT), based on the definitions by Amoaku et al. ${ }^{20}$

\section{Chemokine receptor expression levels}

We performed flow cytometric analysis on venous blood samples within 4 hours of phlebotomy. A blood volume containing $5 \times 10^{5}$ leucocytes (calculated using Sysmex KX-21N, Sysmex Corporation, Kobe, Japan) was separated. Erythrocytes were lysed for 10 min with $10 \%$ red blood cell lysis buffer (Nordic Biosite AB, Täby, Sweden) in the dark at room temperature. Cells were then centrifuged at $500 \mathrm{G}$ and resuspended in isotonic buffer (IsoFlow Sheath Fluid; Beckman Coulter, Brea, CA, USA) three times. Fluorochrome-coupled antibodies were added to the solution (see online supplementary files 1 and 2 for a complete list of antibodies). Corresponding 

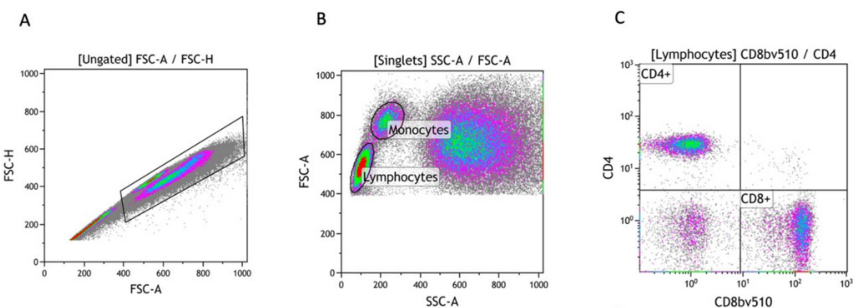

D

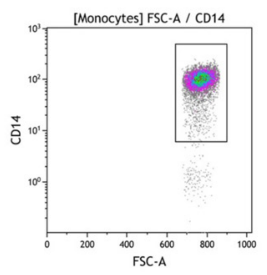

$\mathrm{E}$

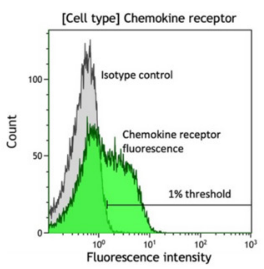

Figure 1 Gating strategy in flow cytometry analysis. (A) Identification of singlets using FSC-A versus FSC-H. (B) Subtyping of singlets into monocytes and lymphocytes using FSC-A versus SSC-A. (C) Isolation of $\mathrm{CD}^{+}{ }^{+}$/ $\mathrm{CD}^{+}$lymphocytes using fluorochrome-coupled specific antibodies. (D) Isolation of CD14 ${ }^{+}$monocytes using fluorochrome-coupled specific antibodies. (E) A general example of quantification of chemokine receptor (eg, CCR1) positive cells using a fluorescence histogram and a negative isotype control with a threshold of $1 \%$. FSC-A, front scatter area; FSC-H, front scatter height; SSC-A, side scatter area.

isotype controls of each antibody was measured in a separate tube. The sample was incubated in the dark at room temperature and was subsequently washed and resuspended in $600 \mu \mathrm{L}$ isotonic buffer. Cells were analysed using the BD FACSCanto II flow cytometer (BD Biosciences, Franklin Lakes, NJ, USA) and Kaluza Software V.1.5.20365.16139 (Beckman Coulter, Pasadena, CA, USA).

A forward scatter area versus a forward scatter height plot was used to identify singlets (figure 1A). Lymphocytes and monocytes were gated using a forward scatter area versus a side scatter area plot (figure 1B). Lymphocytes were further divided into $\mathrm{CD} 4^{+}$and $\mathrm{CD} 8^{+}$ cells according to their expression of CD4 and CD8 (figure 1C). Monocytes were similarly gated for CD14 expression (figure 1D). For each of the three cell types, we identified chemokine receptor positive cells from a histogram of fluorescence from the respective fluorochrome-coupled specific antibodies and used negative isotype controls (at 1\% thresholds) to eliminate fluorescence noise from unspecific binding (figure 1E).

\section{Data analysis}

Normally distributed data werepresented as mean and 95\% CIs and compared using the one-way analysis of variance. Not-normally distributed data were presented as median and IQR and were compared using the Kruskal-Wallis rank test. For categorical data, we used Fisher's exact test. Correlation coefficients were calculated using Spearman's rank (since chemokine receptor expression levels were not normally distributed). To calculate the
OR of potential risk factors for treatment failure, univariate logistic regression analyses were performed.

Statistical analysis was done using R V.3.4.2 for Mac OS X (The R Foundation for Statistical Computing, Vienna, Austria) and SPSS V.24.0.0.0, 32-bit edition. Group-specific correlation networks were drawn using the qgraph extension package for R V.1.4.4. ${ }^{23}$ Correlation coefficients with a value of $0.4-1.0$ were included in the correlation networks with increasing edge width, indicating a stronger correlation.

\section{RESULTS}

Seventy-nine patients were enrolled in the study. We excluded 14 in total: 7 due to incomplete data, 1 due to poor OCT image quality, 3 due to interrupted treatment regimen and 3 due to CRP levels above $15 \mathrm{mg} / \mathrm{L}$. This left 65 eligible patients for analysis. The group of patients with good response to treatment were older than the partial and non-responders $(p=0.007)$ but did not differ significantly in other demographic or clinical characteristics presented in table 1 . Overall, patients' Visual acuity improved; good morphological responders gained in average 7.0 letters (SD 9.8), partial responders gained in average 4.1 letters (SD 12.0) and non-responders gained 3.5 letters (SD 8.6).

Chemokine receptor expression levels were compared between response groups as shown in table 2. We found that patients with no response to treatment had a higher proportion of $\mathrm{CCR}^{+}$monocytes $(\mathrm{p}=0.016)$ and a lower proportion of $\mathrm{CD}^{+} \mathrm{CCR} 3^{+} \mathrm{T}$ cells $(\mathrm{p}=0.037)$.

The chemokine receptor expression levels on monocytes, $\mathrm{CD}^{+}$Tcells and $\mathrm{CD}^{+}$Tcells were investigated using group-specific correlation networks (figure 2). These networks revealed several intergroup differences in chemokine receptor expression level correlations, thus suggesting a more complex systemic chemokine receptor expression pattern in patients with no response to anti-VEGF. In particular, we notice that expression of CCR2 on monocytes shifts towards a more central role in patients with a lack of response to treatment.

We found an age difference between groups, and this raised the question of whether the altered expression and increased complexity of the chemokine receptor correlation network in the non-response group could be merely an age-related phenomenon. In order to investigate this issue, we calculated correlations between age and expression levels and found that age was not strongly correlated $(\mathrm{rho}<0.4, \mathrm{p}>0.1)$ to any chemokine receptor expression level. We further divided all participants, regardless of treatment response, into tertiles $(n=22, n=22, n=21)$ by age (ages ranging from 59-73 yars, 74-80 years and 81-93 years). This revealed that the younger participants, in general, had a less complex chemokine receptor profile than the older ones, thus contradicting that young age could explain the observed increased complexity of the non-responders' immune systems. Lastly, we performed the Kruskal-Wallis test on chemokine receptor expression level data while using the age categories instead of 
Table 1 Baseline characteristics of participants in groups according to their response to anti-VEGF treatment

\begin{tabular}{|c|c|c|c|c|}
\hline Response to anti-VEGF loading dose & Good & Partial & Non-response & $P$ value \\
\hline No. of patients, $n$ & 28 & 27 & 10 & \\
\hline \multicolumn{5}{|l|}{ Demographic characteristics } \\
\hline Age, mean $(95 \% \mathrm{Cl})$ & 79.5 (76.9 to 82.2$)$ & 75.9 (72.7 to 79.0$)$ & $71.1(67.4$ to 74.8$)$ & $0.007^{*}$ \\
\hline Females, \% & 60.7 & 51.9 & 40.0 & $0.534 \dagger$ \\
\hline Body mass index, mean $(95 \% \mathrm{Cl})$ & 25.6 (23.7 to 27.3$)$ & 26.1 (24.0 to 28.3 ) & 25.1 (21.0 to 29.2$)$ & $0.840^{*}$ \\
\hline \multicolumn{5}{|l|}{ Smoking status } \\
\hline Current, \% & 17.9 & 29.6 & 40.0 & $0.462 \dagger$ \\
\hline Former, \% & 46.4 & 44.4 & 50.0 & \\
\hline Never, \% & 35.7 & 25.9 & 10.0 & \\
\hline Alcohol (units/week), median (IQR) & $3.8(0.5-9)$ & $6.0(1.0-10.0)$ & $3.5(1.0-10.0)$ & $0.828 \ddagger$ \\
\hline Regular exercise, \% & 57 & 63 & 70 & $0.789 \dagger$ \\
\hline Hypertension, \% & 64 & 41 & 40 & $0.174 \dagger$ \\
\hline Hypercholesterolaemia, \% & 43 & 19 & 20 & $0.125 \dagger$ \\
\hline Cardiovascular disease, $\%$ & 32 & 22 & 30 & $0.702 \dagger$ \\
\hline Type 2 diabetes, \% & 18 & 4 & 0 & $0.152 \dagger$ \\
\hline \multicolumn{5}{|l|}{ Retinal characteristics } \\
\hline $\begin{array}{l}\text { Central retinal thickness, } \mu \mathrm{m} \text {, median } \\
(\mathrm{IQR})\end{array}$ & $385(313-476)$ & $432(338-552)$ & $412(351-550)$ & $0.475 \ddagger$ \\
\hline $\begin{array}{l}\text { Best-corrected visual acuity (ETDRS } \\
\text { letters), median (IQR) }\end{array}$ & 69 (56-79) & $63(50-73)$ & $61.5(50-73)$ & $0.264 \ddagger$ \\
\hline Intraretinal oedema, \% & 75 & 52 & 60 & $0.294 \dagger$ \\
\hline Subretinal oedema, \% & 71 & 93 & 90 & $0.063 \dagger$ \\
\hline \multicolumn{5}{|l|}{ Treatment } \\
\hline Aflibercept, \% & 71 & 48 & 50 & $0.187 \dagger$ \\
\hline Ranibizumab, \% & 29 & 52 & 50 & \\
\hline
\end{tabular}

*Analysis of variance.

†Fisher's exact test.

$\ddagger$ Kruskal-Wallis test.

VEGF, vascular endothelial growth factor.

treatment response categories. None of the chemokine receptor expression levels differed significantly between the age tertiles (data not shown).

\section{DISCUSSION}

Non-response to anti-VEGF remains an important issue with severe consequences for the patients. Both the innate and the adaptive immune systems are involved in the pathogenesis of AMD, but data on treatment response is sparse. Lechner et al found no correlation between leucocyte subtypes and number of injections in a 1-year follow-up period. ${ }^{24}$ Falk et al found no difference in $\mathrm{CCR}^{+}$granulocytes in patients with good BCVA response compared with those with poor BCVA response. ${ }^{16}$ Apart from these two studies, the relationship between monocyte and lymphoid chemokine expression and treatment response remains unexplored.

Our findings demonstrate that non-responders after loading dose have a more complex peripheral chemokine receptor profile compared with good responders. The concept of correlation networks provides a valuable and illustrative way of describing changes in an integrated system like the immune system. ${ }^{85}$ There are some noticeable differences in correlations between single chemokine receptors, for example, CD $14^{+} \mathrm{CCR} 2^{+}$, which in the good responders only correlates to other monocyte-expressed receptors $\left(\mathrm{CD} 14^{+} \mathrm{CCR} 1^{+}\right.$and $\mathrm{CD} 14^{+} \mathrm{CCR} 5^{+}$), while it correlates to several lymphocyte receptors in the partial and non-response groups. Interestingly, CCR2 ${ }^{+}$monocytes have been strongly linked to late-stage AMD. ${ }^{10-12}$ Retinal injury and inflammation increases intraocular levels of CCR2 ligand (CCL2), ${ }^{10}$ and subsequently, $\mathrm{CCR}^{+}$monocytes are recruited to the inflamed retina. ${ }^{11}$ The correlations of $\mathrm{CD}_{14} 4^{+} \mathrm{CCR} 2^{+}$ could be a sign of an altered inflammation mechanism in the non-response group. The $\mathrm{CD}_{1} 4^{+} \mathrm{CCR} 2^{+}$correlations are also interesting in the context of our previous study, in which we showed an upregulation of CCR2 in patients with neovascular AMD, which was only significant on non-classical proinflammatory monocytes. ${ }^{12}$ This upregulation has also been demonstrated by Grunin et $a l^{17}$ In the present study, we did not differentiate between 
Table 2 Chemokine receptor expression level frequencies, \%, median (IQR)

\begin{tabular}{|c|c|c|c|c|c|c|c|}
\hline $\begin{array}{l}\text { Response to anti-VEGF } \\
\text { loading dose }\end{array}$ & Good & & Partia & & Non-r & & $P$ value \\
\hline $\mathrm{CD} 14^{+} \mathrm{CCR} 1^{+}$ & 36.9 & $(19-58.8)$ & 21.7 & (12.3-31.5) & 63.4 & $(58.2-57.2)$ & $0.016 \dagger$ \\
\hline $\mathrm{CD}_{14}{ }^{+} \mathrm{CCR} 2^{+}$ & 93.1 & $(82.1-97.1)$ & 87.7 & (79.4-94) & 93.6 & (89.2-98.4) & 0.169 \\
\hline $\mathrm{CD}_{14}{ }^{+} \mathrm{CCR}^{+}$ & 0.4 & $(0.2-0.6)$ & 0.2 & $(0.2-0.4)$ & 0.2 & $(0.2-0.3)$ & 0.103 \\
\hline $\mathrm{CD}_{14}{ }^{+} \mathrm{CCR}^{+}$ & 1 & $(0.3-2.1)$ & 0.7 & $(0.4-1.4)$ & 1.7 & $(0.4-2)$ & 0.479 \\
\hline $\mathrm{CD} 14^{+} \mathrm{CXCR}^{+}$ & 0.9 & $(0.6-1.7)$ & 0.8 & $(0.4-1.4)$ & 0.7 & $(0.4-2.3)$ & 0.414 \\
\hline $\mathrm{CD}_{14}{ }^{+} \mathrm{CX} 3 \mathrm{CR} 1^{+}$ & 35.9 & $(26.1-67.3)$ & 40.1 & $(21.3-64.1)$ & 24.3 & (17.3-55) & 0.500 \\
\hline $\mathrm{CD}^{+} \mathrm{CCR}^{+}{ }^{+}$ & 0.2 & $(0.2-0.4)$ & 0.1 & $(0-0.2)$ & 0.1 & $(0-9.5)$ & 0.591 \\
\hline $\mathrm{CD}^{+}{ }^{+} \mathrm{CCR} 2^{+}$ & 5.1 & $(4.1-9)$ & 5.1 & (3.7-6.6) & 7.2 & $(6.1-8.7)$ & 0.479 \\
\hline $\mathrm{CD}^{+}{ }^{+} \mathrm{CCR}^{+}{ }^{+}$ & 0.3 & $(0.2-0.4)$ & 0.2 & $(0.1-0.3)$ & 0.2 & $(0.1-0.2)$ & 0.264 \\
\hline $\mathrm{CD}^{+}{ }^{+} \mathrm{CCR} 5^{+}$ & 2.7 & $(1.2-5.3)$ & 1.8 & $(1.1-2.5)$ & 4.2 & $(1.9-7.9)$ & 0.130 \\
\hline $\mathrm{CD}^{+}{ }^{+} \mathrm{CXCR}^{+}$ & 2.5 & $(1.6-5)$ & 3.2 & $(1-5.1)$ & 2 & $(1.5-3)$ & 0.645 \\
\hline $\mathrm{CD}^{+} \mathrm{CCR}^{+}{ }^{+}$ & 0.2 & $(0.2-0.4)$ & 0.3 & $(0.1-0.6)$ & 0.5 & $(0.1-2.8)$ & 0.811 \\
\hline $\mathrm{CD}^{+}{ }^{+} \mathrm{CCR} 2^{+}$ & 7.8 & $(4.9-12)$ & 7.5 & $(5.7-9.2)$ & 7.8 & $(4.7-8.7)$ & 0.687 \\
\hline $\mathrm{CD}^{+} \mathrm{CCR}^{+}$ & 0.5 & $(0.4-0.8)$ & 0.4 & $(0.4-0.7)$ & 0.3 & $(0.1-0.4)$ & $0.037 \dagger$ \\
\hline $\mathrm{CD}^{+} \mathrm{CCR}^{+}$ & 12.6 & $(4.5-23.1)$ & 9.4 & $(4.7-14.7)$ & 17 & (9.6-23.9) & 0.195 \\
\hline $\mathrm{CD}^{+} \mathrm{CXCR}^{+}$ & 4 & $(1.9-6.3)$ & 4.2 & $(1.3-8.6)$ & 3.3 & $(1.4-9.1)$ & 0.978 \\
\hline
\end{tabular}

*Fisher's exact test.

†Statistically significant.

monocyte subsets, and the differences between the three groups might have been even clearer if we had isolated the non-classical monocyte subset.

Furthermore, we found an increased $\mathrm{CD} 14^{+} \mathrm{CCR} 1^{+}$and a decreased $\mathrm{CD} 8^{+} \mathrm{CCR}^{+}{ }^{+}$expression level in the non-response group. Previous research has demonstrated a significant increase of $\mathrm{CCR}^{+}$proinflammatory (non-classical) monocytes in patients with neovascular AMD compared with healthy controls. ${ }^{17}$ In a mouse model for retinal degeneration, CCR1 expression was found to be
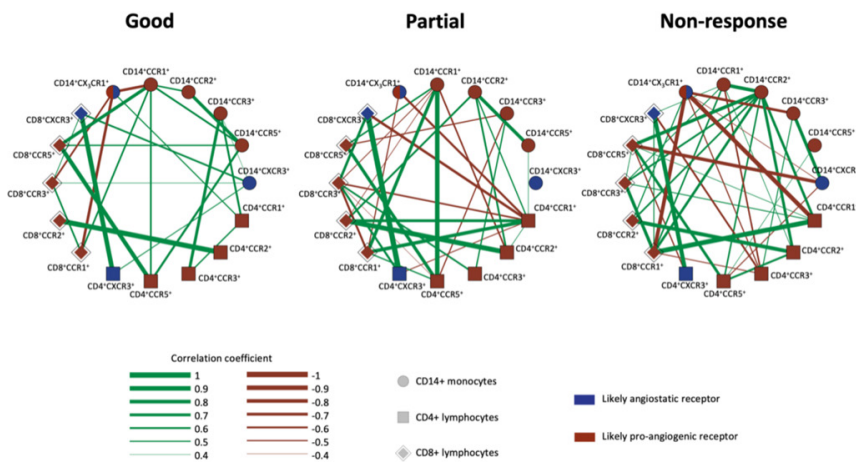

Figure 2 Correlation networks of chemokine receptor expression on peripheral blood leucocytes. The correlation networks illustrate that patients with no response to antiVEGF treatment (increased CRT at follow-up) have a more complex chemokine receptor profile than patients with a partial response (CRT reduced by $0 \%-75 \%$ at follow-up) and patients with a good response to treatment (CRT reduced by $<75 \%$ or full resorption of subretinal and intraretinal fluid). CRT, central retinal thickness; VEGF, vascular endothelial growth factor. upregulated in photoreceptor cells. ${ }^{26}$ CCR1 expression has also been linked to other inflammatory degenerative diseases such as Alzheimer's dementia. ${ }^{27}$ We also found a small change in the proportion of $\mathrm{CD} 8^{+} \mathrm{CCR} 3^{+}$between the treatment groups. CCR3 has been studied as a potential target for neovascular AMD treatment with promising results on murine models. ${ }^{28}$ However, only a very small fraction of the $\mathrm{CD} 8^{+}$cells in our study expressed CCR3 $(0.3 \%-0.5 \%)$. In our gating strategy, we defined expression from negative isotype controls at $1 \%$ thresholds. This breeds a risk of interference when measuring low expression levels.

Important limitations should be considered in interpretation of these data. This was an observational study, and we can only assume that a causal relationship exists regarding treatment response and the observed differences in the chemokine receptor expression. Changes in chemokine receptor expression could potentially be reactive or compensatory mechanisms. We did not measure the intraocular chemokine ligand levels and therefore cannot analyse ligand-receptor interaction in these patients. ${ }^{29}$ Also, the participants included received treatment with two different types of anti-VEGF, which might influence the individual response to the specific drug. Further, our study is limited in sample size, which unfortunately does not allow for multivariate analyses. Larger studies are warranted to allow multivariate analyses to evaluate how these factors associate in more detail, to explore correlations between immunological phenotypes and features visible on detailed imaging such as subretinal fibrosis and hyperreflective foci, and 
to explore potential impact in clinical practice and the prognosis we can give to our patients.

In conclusion, this study finds a more complex chemokine receptor profile on systemic monocytes and leucocytes in patients with neovascular AMD and lack of response to anti-VEGF treatment. This may implicate chemokines in anti-VEGF treatment failure and supports the idea of systemic immunology as a component of neovascular AMD pathogenesis and progression.

\section{Acknowledgements Not applicable.}

Contributors TB, MKN and TLS designed the study. MKN, CRM, YS and TLS obtained funding. TB, MKN, CRM and YS collected the data. TB, MKN and TLS analysed and interpreted the data. TB drafted the manuscript and prepared the figures and tables. All authors critically revised the manuscript for important intellectual content

Funding This study was made possible by grants from the Danish Eye Research Foundation (Taastrup, Denmark), Fight for Sight Denmark (Copenhagen, Denmark), the Velux Foundation (Søborg, Denmark) and the University of Copenhagen (Copenhagen, Denmark). The funding bodies had no role in the design or conduct of this research.

Competing interests None.

Patient consent for publication Not required.

Ethics approval This prospective observational cohort study was conducted in compliance with the Declaration of Helsinki and was approved by the Regional Committee of Ethics in Research in Region Zealand (journal no. SJ-385).

Provenance and peer review Not commissioned; externally peer reviewed.

Data availability statement Dataset can be obtained from the corresponding author upon reasonable request.

Open access This is an open access article distributed in accordance with the Creative Commons Attribution Non Commercial (CC BY-NC 4.0) license, which permits others to distribute, remix, adapt, build upon this work non-commercially, and license their derivative works on different terms, provided the original work is properly cited, appropriate credit is given, any changes made indicated, and the use is non-commercial. See: http://creativecommons.org/licenses/by-nc/4.0/.

\section{REFERENCES}

1. Sedeh FB, Scott DAR, Subhi Y, et al. Prevalence of neovascular agerelated macular degeneration and geographic atrophy in Denmark. Dan Med J 2017;64:64-7.

2. Owen CG, Jarrar Z, Wormald R, et al. The estimated prevalence and incidence of late stage age related macular degeneration in the UK. Br J Ophthalmol 2012;96:752-6.

3. Lim LS, Mitchell P, Seddon JM, et al. Age-Related macular degeneration. The Lancet 2012;379:1728-38.

4. Gillies MC, Campain A, Barthelmes D, et al. Long-Term outcomes of treatment of neovascular age-related macular degeneration: data from an observational study. Ophthalmology 2015;122:1837-45.

5. Yang S, Zhao J, Sun X. Resistance to anti-VEGF therapy in neovascular age-related macular degeneration: a comprehensive review. Drug Des Devel Ther 2016;10:1857-67.

6. Kauppinen A, Paterno JJ, Blasiak J, et al. Inflammation and its role in age-related macular degeneration. Cell Mol Life Sci 2016;73:1765-86.

7. Subhi Y, Singh A, Falk MK, et al. In patients with neovascular age-related macular degeneration, physical activity may influence C-reactive protein levels.. Clin Ophthalmol 2014;4:15-21.
8. Singh $A$, Subhi $Y$, Krogh Nielsen $M$, et al. Systemic frequencies of $T$ helper 1 and Thelper 17 cells in patients with age-related macular degeneration: a case-control study. Sci Rep 2017;7:605.

9. Combadière C, Feumi C, Raoul W, et al. CX3CR1-dependent subretinal microglia cell accumulation is associated with cardinal features of age-related macular degeneration. J Clin Invest 2007:117:2920-8.

10. Raoul W, Auvynet C, Camelo S, et al. CCL2/CCR2 and CX3CL1/ CX3CR1 chemokine axes and their possible involvement in agerelated macular degeneration. J Neuroinflammation 2010;7:87.

11. Sennlaub F, Auvynet C, Calippe B, et al. CCR2 ${ }^{(+)}$monocytes infiltrate atrophic lesions in age-related macular disease and mediate photoreceptor degeneration in experimental subretinal inflammation in Cx3cr1 deficient mice. EMBO Mol Med 2013;5:1775-93.

12. Subhi $\mathrm{Y}, \mathrm{Krogh}$ Nielsen $\mathrm{M}$, Molbech $\mathrm{CR}$, et al. Altered proportion of CCR2 + and CX3CR1 + circulating monocytes in neovascular agerelated macular degeneration and polypoidal choroidal vasculopathy. Clin Exp Ophthalmol 2019;47:69-78.

13. Krogh Nielsen M, Hector SM, Allen K, et al. Altered activation state of circulating neutrophils in patients with neovascular age-related macular degeneration. Immun Ageing 2017;14:1-9.

14. Falk MK, Singh A, Faber $\mathrm{C}$, et al. $\mathrm{C} \times 3 \mathrm{Cl} 1 / \mathrm{C} \times 3 \mathrm{Cr} 1$ and $\mathrm{CCL} 2 / \mathrm{CCR} 2$ chemokine/chemokine receptor complex in patients with AMD. PLoS One 2014;9:e112473-15.

15. Falk MK, Singh A, Faber C, et al. Dysregulation of CXCR3 expression on peripheral blood leukocytes in patients with neovascular agerelated macular degeneration. Invest Ophthalmol Vis Sci 2014;55.

16. Falk MK, Singh A, Faber $C$, et al. Blood expression levels of chemokine receptor CCR3 and chemokine CCL11 in age-related macular degeneration: a case-control study. BMC Ophthalmol 2014;14:1-7.

17. Grunin M, Burstyn-Cohen T, Hagbi-Levi S, et al. Chemokine receptor expression in peripheral blood monocytes from patients with neovascular age-related macular degeneration. Invest Ophthalmol Vis Sci 2012;53:5292-300.

18. Subhi Y, Sørensen TL. Physical activity patterns in patients with early and late age-related macular degeneration.. Dan Med J 2016;63:1-5.

19. Bürgisser P, Vaudaux J, Bart P-A. Severe interference between retinal angiography and automated four-color flow cytometry analysis of blood mononuclear cells. Cytometry 2007;71A:632-6.

20. Amoaku WM, Chakravarthy $U$, Gale R, et al. Defining response to anti-VEGF therapies in neovascular AMD. Eye 2015;29:721-31.

21. Nguyen V, Daien V, Guymer R, et al. Projection of long-term visual acuity outcomes based on initial treatment response in neovascular age-related macular degeneration. Ophthalmology 2019;126:64-74.

22. Bloch SB. Implementation studies of ranibizumab for neovascular age-related macular degeneration. Acta Ophthalmol 2013;91 Thesis7(Suppl):1-22.

23. Epskamp S, Cramer AOJ, Waldorp LJ, et al. qgraph : Network Visualizations of Relationships in Psychometric Data. J Stat Softw 2012;48.

24. Lechner J, Chen M, Hogg RE, et al. Peripheral blood mononuclear cells from neovascular age-related macular degeneration patients produce higher levels of chemokines CCL2 (MCP-1) and CXCL8 (IL8). J Neuroinflammation 2017;14:12.

25. Britschgi M, Wyss-Coray T. Blood protein signature for the early diagnosis of Alzheimer disease. Arch Neurol 2009;66:161.

26. Zeng $\mathrm{H}$-yang, Lu Q-jun, Liu Q, et al. The role of CCR1 expression in the retinal degeneration in RD mice. Curr Eye Res 2011;36:264-9.

27. Halks-Miller M, Schroeder ML, Haroutunian V, et al. Ccr1 is an early and specific marker of Alzheimer's disease. Ann Neurol 2003;54:638-46.

28. Takeda A, Baffi JZ, Kleinman ME, et al. Ccr3 is a therapeutic and diagnostic target for neovascular age-related macular degeneration. Nature 2009;460:225-30.

29. Green SB. How many subjects does it take to do a regression analysis. Multivariate Behav Res 1991;26:499-510. 